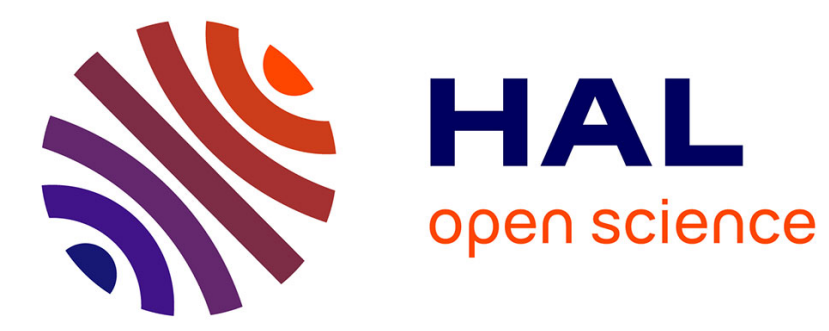

\title{
MORPHOLOGY AND RESISTIVITY OF CVD POLYCRYSTALLINE SILICON LAYERS CONTAINING CARBON
}

\author{
M. Hendriks, S. Radelaar, Th. de Keijser, R. Delhez
}

\section{- To cite this version:}

M. Hendriks, S. Radelaar, Th. de Keijser, R. Delhez. MORPHOLOGY AND RESISTIVITY OF CVD POLYCRYSTALLINE SILICON LAYERS CONTAINING CARBON. Journal de Physique Colloques, 1982, 43 (C1), pp.C1-307-C1-312. 10.1051/jphyscol:1982141 。 jpa-00221798

\section{HAL Id: jpa-00221798 https://hal.science/jpa-00221798}

Submitted on 1 Jan 1982

HAL is a multi-disciplinary open access archive for the deposit and dissemination of scientific research documents, whether they are published or not. The documents may come from teaching and research institutions in France or abroad, or from public or private research centers.
L'archive ouverte pluridisciplinaire HAL, est destinée au dépôt et à la diffusion de documents scientifiques de niveau recherche, publiés ou non, émanant des établissements d'enseignement et de recherche français ou étrangers, des laboratoires publics ou privés. 


\title{
MORPHOLOGY AND RESISTIVITY OF CVD POLYCRYSTALLINE SILICON LAYERS CONTAINING CARBON
}

\author{
M. Hendriks, S. Radelaar, Th.H. de Keijser and R. Delhez \\ Laboratory of MetaZzurgy, Delft University of Technology, Rotterdamseweg \\ 137, 2628 AL Delft, The Netherlands
}

\begin{abstract}
Rësumé
Les auteurs ont étudié l'influence de l'addition de carbone sur la structure cristalline et la resistivité des couches minces de silicium, formées par la décomposition simultanée de $\mathrm{SiH}_{4}, \mathrm{C}_{2} \mathrm{H}_{2}$ et $\mathrm{PH}_{3}$ à $1000^{\circ} \mathrm{C}$. Ils ont déterminé la teneur en carbone, la morphologie, la texture, la taille des grains et les dilatations de rẻseau. On a trouvé que le carbone a un effet prononcé sur la structure cristalline et sur la resistivité de ces couches minces. Il existe une corrélation entre la structure et la resistivite, qui s'explique qualitativement.
\end{abstract}

\section{Abstract}

The influence of the addition of carbon on the crystalline structure and resistivity of polycrystalline silicon layers grown by simultaneous decomposition of $\mathrm{SiH}_{4}, \mathrm{C}_{2} \mathrm{H}_{2}$ and $\mathrm{PH}_{3}$ at $1000^{\circ} \mathrm{C}$ was studied. Carbon content, morphology, preferred orientation, ${ }^{2}$ crystallite size, lattice strains and resistivity were determined. It was found that carbon has a pronounced effect on the crystalline structure and resistivity of the layers. A correlation exists between the structure and resistivity which can be understood qualitatively.

\section{Introduction}

Carbon can be used to influence the resistivity and grain size of polycrystalline silicon layers, as was recently reported by $\mathrm{Bloem}$ and Claassen [1]. Incorporation of small amounts of carbon led to a minimum in the resistivity of phosphorus-doped layers. Higher concentrations led to an increase in resistivity and a reduction in grain size accompanied by the formation of a second phase. Although substitutionally dissolved carbon is considered to be an electrically inactive impurity, it can influence the electrical properties of polycrystalline silicon by causing simultaneously:

(i) a change in grain size (L) and

(ii) a change in the density of traps $\left(Q_{t}\right)$ at the grain boundaries.

It has been firmly established $[2,3]$ that the trapping of charge carriers at grain boundaries plays the most important role in the electrical behaviour of polycrystaline silicon layers. The effects are most pronounced when the product of grain size $L$ and the doping concentration $N$ becomes approximately equal to the density of trapping states $Q_{t}$ :

$$
L \cdot N \simeq Q_{t}
$$

For low dopant concentration $\left(N \ll Q_{t} / L\right)$ nearly all the free charge carriers introduced by doping will be trapped at the grain boundaries and the resistivity will be high due to the formation of potential barriers at the grain boundaries and the low concentration of free charge carriers. For high doping concentrations $\left(N \gg Q_{t} / L\right)$ only a small fraction of the charge carriers are trapped at the grain boundaries, the depletion zone adjacent to the grain boundaries will be small and 
the resistivity will thus approach the value for single crystalline silicon. The most rapid changes of resistivity with dopant concentration are thus expected to occur in the region where eq. (1) is approximately fulfilled. Several authors [3, 4] have refined Seto's mode1 [2]. E.g. Graef [4] introduced a continuous distribution of trapping states instead of identical traps with constant energy $E_{t}$, as assumed by seto. Fig. 1 shows the resistivity as a function of grain size for three

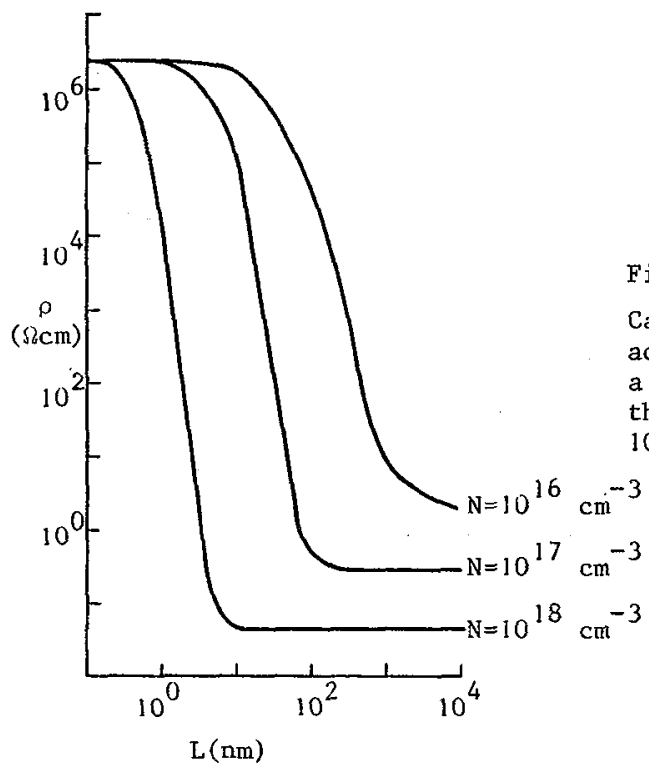

Fig. 1.

Calculated resistivity versus grain size $\mathrm{L}$ according to the carrier trapping model with a continuous distribution of traps thrqughout the gap with density $10^{12}\left(\mathrm{eV}^{-1} \cdot \mathrm{cm}^{-2}\right)$, Graef [4].

different doping concentrations of $10^{16}, 10^{17}$ and $10^{18} \mathrm{~cm}^{-3}$ respectively, using a uniform trap density distribution of $10^{12} \mathrm{eV}^{-1} \cdot \mathrm{cm}^{-2}$. It is evident that the most rapid changes oçcur in the range of grain sizes typical for CVD polycrystalline silicon $\left(1-10^{3} \mathrm{~nm}\right)$. Bloem and $\mathrm{Claassen}$ assumed that smal1 amounts of carbon diminish the number of traps at the grain boundaries. In this paper we will show that small amounts of carbon can also increase the crystallographic perfection of the layers, which can produce marked effects on the resistivity when the grain size is in the region where $L \simeq Q_{t} / N$.

\section{Experimenta1 techniques}

Polycrystalline silicon layers were grown by simultaneous decomposition of $\mathrm{SiH}_{4}\left(0.1\right.$ vol.perc.), $\mathrm{C}_{2} \mathrm{H}_{2}$ (up to $9 \times 10^{-3}$ vol.perc.) and $\mathrm{PH}_{3}$ (O or $8.4 \times 10^{-7}$ vol.perc.) in $\mathrm{H}_{2}$ at 1 atm. and $1000^{\circ} \mathrm{C}$ in a horizontal air cooled reactor at Philips Research, Eindhoven [1]. The substrates were (100) $\mathrm{Si}$ crystals, covered with $0.15 \mu \mathrm{m} \mathrm{SiO}_{2}$ or $\mathrm{Si}_{3} \mathrm{~N}_{4}$ and the poly-Si thickness varied between $3.0 \mu \mathrm{m}$ and $3.5 \mu \mathrm{m}$. We report on three series, two of them were grown under practically identical conditions within an interval of about one year.

The carbon content of the layers was determined by electron probe micro analysis (EPMA). Because fiber type textures were present, the preferred orientation was studied by X-ray diffraction using $\phi$-scans: the (hk1) intensity measured at $\phi$ is proportional to the volume fraction of crystallites with (hkl) planes making an angle $\phi$ with the specimen surface. From $X$-ray diffraction line profile analysis (LPA) information was obtained about (i) the effective particle size $D$ and the r.m.s. of the short-range strains $\varepsilon$ and (ii) the long-range strain. The analysis is based on the fact that imperfections in the crystal like grain boundaries, stacking faults, twins (effective particle size) and dislocations (r.m.s. short-range strain) cause a 
broadening of the Bragg reflections [ 3 ], whereas a long-range strain causes a change in the average lattice parameter and thus a shift in the position of the Bragg reflections [6]. The Warren-Averbach size-strain analysis [5] was applied to calculate $D$ and $\varepsilon$ from two orders of a reflection. The $\sin ^{2} \psi$ method [6] was applied to determine long range stresses from peak shifts. Since a diffractometer with Bragg-Brentano focussing geometry was used, a reflection (hik1) ariginates from crystallites with (hkl) planes parallel to the specimen surface. Consequently, D and $\varepsilon$ relate to those crystallites only and represent the effective particle size and r.m.s. short-range strain in the direction normal to the layer surface. Because a $\langle 110\rangle$ fiber texture occurred in the layers, the (220) and (440) reflections were chosen, thus providing information about a relatively large fraction of crystallites. kiorphology was studied by scanning and transmission electron microscopy (SEMi and TEM). We think the results of the line profile analysis are very useful here because they are a measure of the crystallographic perfection which relates to the resistivity, whereas SEM yields the outer size and shape of clusters. Resistivity was determined by the four point probe method. The number of incorporated $P$ atoms in the poly-Si layers was determined from the resistivity of a simultaneously grown monocrystalline epitaxial layer.

Irvin plots [7] were used to relate the resistivity of the monocrystalline layer to the number of dopant atoms and it was assumed that the number of incorporated dopant atoms is the same for both types of layers.

\section{Results}

The total carbon concentration present in the layers as measured by means of EPNA is shown in Fig. 2. The carbon concentration is not lineairly related to the $\mathrm{C}_{2} \mathrm{H}_{2}$

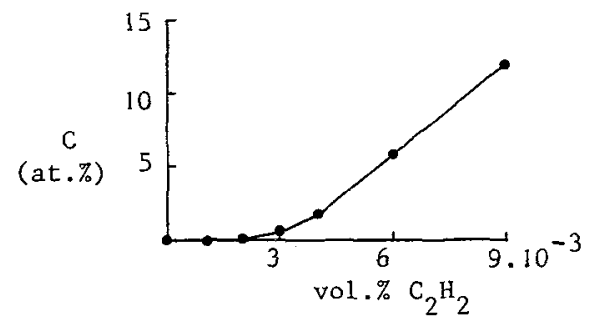

Fig. 2.

Carbon content $\mathrm{C}$ versus $\mathrm{C}_{2} \mathrm{H}_{2}$ concentration during growth at $1000^{\circ} \mathrm{C}$ for poly-Si on $\mathrm{Si}_{3} \mathrm{~N}_{4}$, no dope, thickness poly-Si $=3.5 \mu \mathrm{m}$.

concentration but increases rapidly after a comparatively slow initial increase. The change-over occurs at about $3 \times 10^{-3}$ vol.perc. $\mathrm{C}_{2} \mathrm{H}_{2}$ or 1 atomic percent carbon. This amount greatly exceeds the solubility of carbon in silicon at this temperature $\left(\simeq 10^{10} \mathrm{~cm}^{-3}\right)$, which corresponds to $\approx 2 \times 10^{-5}$ at.perc. C [8]. For $\mathrm{C}_{2} \mathrm{H}_{2}$ concentrations higher than $3 \times 10^{-3}$ vol.perc. precipitation of $B-S i C$ particles at the grain boundaries was observed by means of TEM.

The layers without carbon showed a $\langle 110\rangle$ fiber texture, gradually disappearing with increasing carbon content. SEM revealed large, facetted, columar grains and a rough surface for layers without carbon, changing to smaller, equi-axed grains and a relatively smooth surface for the layers with a high carbon content. Fig. 3 shows the effective particle size as a function of the $\mathrm{C}_{2} \mathrm{H}_{2}$ concentration for both undoped layers and layers with a phosphorus content of $23 \times 10^{17} \mathrm{~cm}^{-3}$. The introduction of carbon at first does not affect the particle size so much but at $3 \times 10^{-3}$ vol.perc. $\mathrm{C}_{2} \mathrm{H}_{2}$ a pronounced maximum is found. At higher $\mathrm{C}_{2} \mathrm{H}_{2}$ concentrations a rapid decrease in effective particle size is observed. Although the grain sizes as determined from the SEM micrographs are in the same range as those from the line profile analysis, the pronounced maximum could not be found in the micrographs. Fig. 3 further shows that a larger particle size is accompanied by a lower short-range strain, both indicating a more perfect crystalline structure. The layers contained tensile stresses as high as $2.4 \times 10^{2} \mathrm{MPa}$, which is quite high as compared to the breaking strength of $\mathrm{Si}$ in 


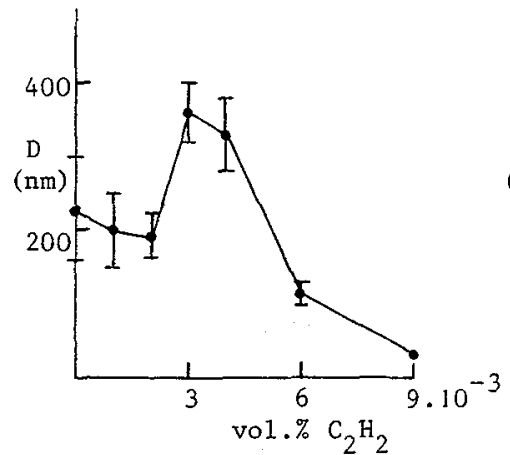

(a)

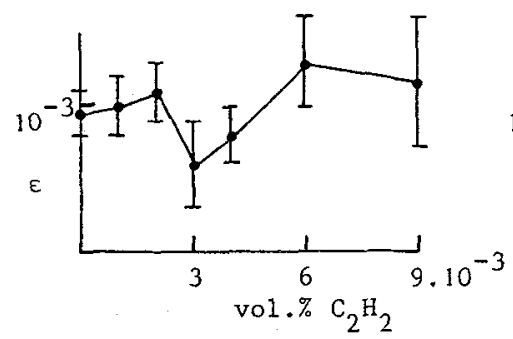

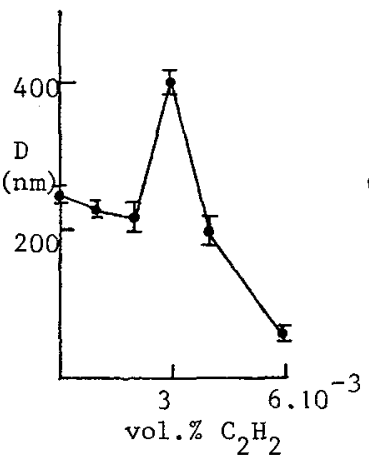

(b)

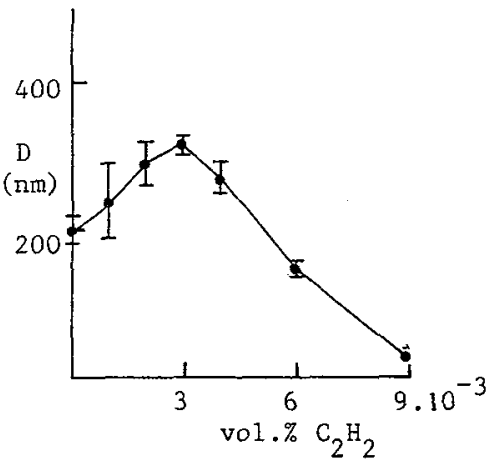

(c)
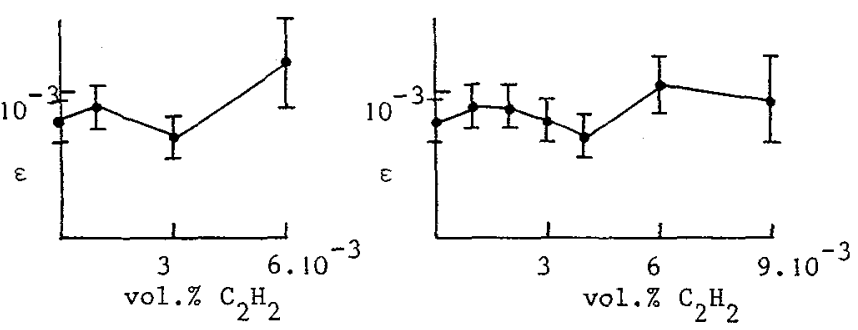

rig. 3. Effective particle size D and r.m.s. short-range strain $\varepsilon$ of poly-Si 1 ayers versus $\mathrm{C}_{2} \mathrm{H}_{2}$ concentration during growth at $1000^{\circ} \mathrm{C}$ in $\mathrm{H}_{2}$ with the following characteristics:

a - substrate $\mathrm{Si}_{3} \mathrm{~N}_{4}$, no dope, thichness poly-Si $=3.5 \mathrm{\mu m}$

b, c - substrate $\mathrm{SiO}_{2}$, P-dope $3.10^{17} \mathrm{~cm}^{-3}$, thickness poly-Si $=3.0 \mu \mathrm{m}$.

$D$ and $\varepsilon$ are determined from X-ray diffraction line profile analysis.

(a)

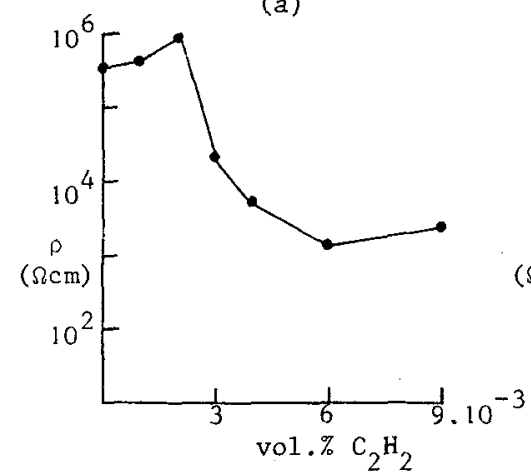

(b)

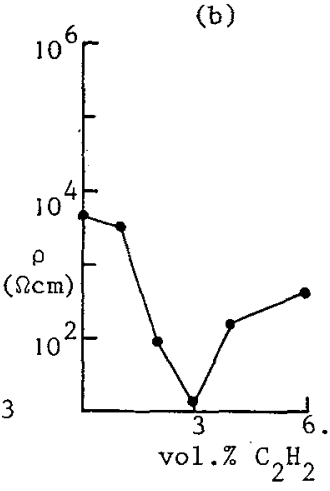

(c)

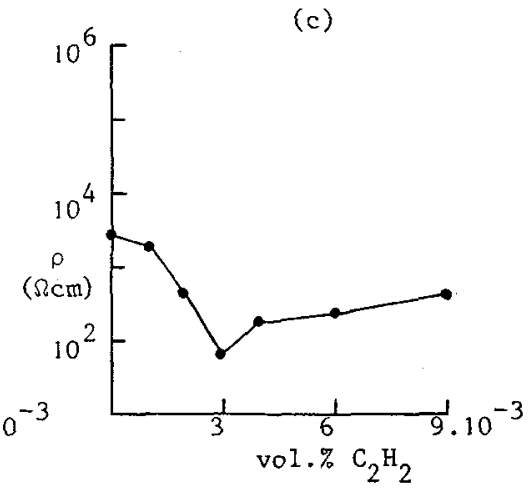

Fig. 4. Resistivity (four point probe) versus $\mathrm{C}_{2} \mathrm{H}_{2}$ concentration during growth, see further caption Fig. 3. 
compression: $5.0 \times 10^{2} \mathrm{NPa}$ [9]. The resistivity curves (Fig. 4) show a strong correlation with the curves for the effective particle size. In particular the appearance of a minimum in $\rho$ at the $\mathrm{C}_{2} \mathrm{H}_{2}$ concentration for which a maximum in $D$ occurs is rather striking. For the undoped layers (Fig. 4a) the resistivity remains practically constant after the precipitous decrease around the $\mathrm{C}_{2} \mathrm{H}_{2}$ concentration of $3 \times 10^{-3}$ vol:perc.

\section{Discussion}

The initial increase in the effective particle size $D$ with increasing carbon concentration is rather unexpected. Heasurements of the average grain size by means of SEY and TEM only show a monotonous decrease with increasing carbon content. One has to keep in mind however that these techniques measure different characteristics of a given assembly of grains. The effective particle size D is a measure for the imensions of coherently scattering domains in a direction perpendicular to the layer, whereas the average grain size L determined from SEM or TEM micrographs is a measure of the average distance between large angle boundaries in a direction parallel to the layer. The two measures $D$ and $L$ may differ significantly, especially for coarse grained materials.

The initial increase of the effective particle size $D$ with increasing carbon content is not easy to explain. A possible cause for this effect could be the influence of carbon on the stacking fault energy in silicon. Lowering of the stacking fault energy would lead to an increase in the density of twins. Twins laying parallel to the growth direction play a role in the growth of polysilicon and probably are the cause of the $\langle 110\rangle$ type fiber texture commonly observed in polysilicon layers grown by CVD.

The formation of $\mathrm{B}-\mathrm{SiC}$ particles for layers grown at $\mathrm{C}_{2} \mathrm{H}_{2}$ concentrations above $3.10^{-3}$ vol.perc. causes a strong reduction in effective particle size. The sudden increase in carbon uptake for these layers is also likely due to the presence of SiC. Apparently a certain amount of supersaturation of $\mathrm{C}_{2} \mathrm{H}_{2}$ is needed to make the nucleation of SiC possible.

There is a striking correlation between the maximum in the effective particle size and the minimum in the resistivity of the films doped with phosphorus. Such a minimum in the resistivity as a function of carbon content for n-type layers $\left(\mathrm{N} \sim 10^{17} \mathrm{~cm}^{-3}\right)$ grown at $850^{\circ} \mathrm{C}$ was also observed by Bloem et al. [1]. These authors explain the existance of a minimum by a compensation of dangling bonds due to the incorporation of carbon in the grain boundaries. The subsequent increase in the resistivity is thought to be due to the decrease in grain size induced by the carbon addition. This explanation implies that the condition given by eq. (1) is approximately fulfilled. Using the value of the grain size of 0.1 um reported in their paper the trapping density near the resistivity minimum is found to be of the order of $1.01^{12} \mathrm{~cm}^{-2}$. This value is indeed sqmewhat lower than the values reported by Seto $\left(3.3 \times 10^{12} \mathrm{~cm}^{-2}\right)$ and Graef $\left(3.10^{12} \mathrm{~cm}^{2}\right)$. Our X-ray measurements show that the perfection of the crystallites is greatest around the resistivity minimum. Part of the decrease in resistivity will thus be due to this effect. The resistivity of undoped layers also decrease suddenly with increasing carbon content at the point where the maximum in $D$ and the minimum in $\varepsilon$ is observed. This effect indicates that carbon itself contrary to the expectation expressed in the introduction is an electrically active impurity. It is likely that there is a relation between this electrical activity and the presence of SiC or of SiC-Si interfaces.

It is concluded that carbon has a pronounced effect on the morphology and resistivity of polycrystalline silicon layers and that the two effects are closely related.

\section{Acknowledgement}

The authors thank prof. J. Bloem and dr. W.A.P. Claassen of Philips Research, Eindhoven for many stimulating discussions; they also provided the specimens. The texture was measured by Mr. N.M. van der Pers. Ir. D. Schalkoord and Mr. D. Nelemans performed the EPLIA and SEM and Mr. F. Verhagen the TEM. The long-range strain was measured in cooperation with Ir. P.F. Willemse of Twente University of Technology. 
Mr. R. Spekhorst assisted with the resistivity measurements. This work is part of the research program of the Stichting voor Fundamenteel Onderzoek der Materie and was made possible by financial support from the Nederlandse Organisatie voor ZuiverWetenschappe1ijk Onderzoek.

\section{References}

1. J. Bloem, W.A.P. Claassen, App1.Phys.Letters 40(1982) 725 .

2. J.Y.W. Seto, J.App1.Phys. 46(1975)5247.

3. G. Baccarani, B. Ricco and G. Spadini, J.App1.Phys. 49 (1978) 5565.

4. M.W. M. Graef, Thesis Nijmegen (1980).

5. B.E. Warren, X-ray Diffraction, Addison-Wesley (1969).

6. B.D. Cullity, Elements of X-ray Diffraction, Addison-Wesley (1978), pp. 447-478.

7. J.C. Irvin, Bell System Techn.J. 41(1962) 387-410.

8. A.R. Bean and R.C. Newman, J.Phys.Chem. Solids 32(1971)1211.

9. W.R. Runyan, Silicon Semiconductor Technology, McGraw-Hill, (1965), p. 213. 